\title{
Не платят налоги вокруг, не заплатите и Вы или пространственно-авторегрессионный анализ склонности к нарушению налогового законодательства
}

\section{Артур Нагапетян*, Мария Бонячук, Валерия Григорьева}

Дальневосточный федеральный университет, Владивосток, Россия

\author{
Информация о статье \\ Поступила в редакциию: \\ 15.02 .2021 \\ Принята \\ к опубликованию: \\ 26.02.2021 \\ УДК 330.43 \\ JEL H26
}

\section{Ключевые слова:}

налог, ФСС, финансовое поведение, нарушение, фактор, пространственно-авторегрессионный анализ, склонность к уклонению от уплаты налогов

\section{Keywords:}

tax, SSF, financial behavior, violation, determinant, spatialautoregressive analysis, the tendency to tax evasion

\begin{abstract}
Аннотация
В работе оченивается влияние показателя склонности уклонения от налогообложения в одних регионах Российской Федерации на этот же показатель в соседних регионах. В том числе было оченено влияние следующих факторов: уровень образованности, коэффициент демографической нагрузки, уровень преступности, заболеваемости, присутствия женщчин, уровень брачности, безработицы, склонность к кредитованию. Практическая роль настоящей статьи состоит 8 выявлении причин ухода от налоговых сборов, повышении налоговой грамотности и в будущем исключении нарушений налогового кодекса. Полученные результаты могут иметь практический интерес для лии, проектирующих электронные системы налогообложения.
\end{abstract}

\section{Spatial-autoregressive Analysis of Propensity to Violate Tax Laws}

Artur Nagapetyan, Mariya Bonyachuk, Valeriya Grigoryeva

\begin{abstract}
This paper evaluates the impact of the tendency of tax evasion in neighboring regions of the Russian Federation affects the level of the same crimes in a particular region. On the one hand, if economic agents evade taxes in neighboring regions, then similar behavior can also be expected in this region. On the other hand, there may be no connection, for example, because companies consider the risks of, for example, penalties when deciding on tax behavior. It is possible to have the opposite effect, for example, if the environment consistently pays taxes, then to gain a competitive advantage, the economic agent may stop paying them. During the study, we considered a wide range of factors, including socio-economic factors: the real income per capita, level of education, age dependency ratio, the level of development of financial infrastructure in the region, the level of crime, level of morbidity, level of presence of women, the level of marriage rate, unemployment rate, levels of car ownership, propensity to lend, the level of productivity. The impact of some of these factors is ambiguous.

For example, on the one hand, the higher the level of education, the better people understand the tax system, realize the
\end{abstract}

* Автор для связи: nagapetyan_ar@dvfu.ru DOI: https://dx.doi.org/10.24866/2311-2271/2021-1/15-22 
importance of paying taxes and, therefore, do not avoid paying taxes, on the other hand, in this case, people can start using complex tax evasion schemes, while reducing the risk of being caught. Therefore, a specific practical role of this paper is to identify the reasons of tax evasion to increase tax literacy and eliminate violations of the tax law in the future. The results can also have practical interest for those designing electronic tax system.

\section{Введение}

Осознанность людей и их ответственность перед обществом имеют большое значение. В настоящий момент мы фактически находимся в состоянии, когда государство стремится к переходу от жесткого контроля в сфере финансов к гражданской сознательности своих граждан, которые понимают функцию налогов, их роль в экономике и готовы выплачивать их для поддержания страны, в которой они живут.

Чтобы создать благоприятный климат для развития экономики и смягчить контроль против нарушителей нужно спроектировать систему, которая будет выполнять важнейшую роль - создание финансово грамотного населения. Знание факторов, влияющих на нарушение налогового кодекса, может помочь лучше понять систему налогообложения и выстроить ее так, чтобы у налогоплательщиков не было причин нарушать законодательство.

Особенностью данного исследования является рассмотрение широкого круга факторов, в большинстве своем социально-экономических на ряду с пространственными эффектами.

С одной стороны, пространственные эффекты могут оказывать положительное влияние. Если все вокруг платят налоги, то и у индивида нет оснований идти против системы, нет причин рисковать, так как цена для него приемлемая. С другой стороны, у данного эффекта есть и отрицательное влияние: если все вокруг будут уклоняться от налогов, то индивид с большей долей вероятности тоже перестанет платить налоги, так как в данном случае при уплате налогов он утратит конкурентоспособность. Такая связь называется прямо пропорциональной.

Также связь может быть обратно пропорциональной. Если окружение стабильно платит налоги, то чтобы получить конкурентное преимущество индивид может перестать их платить.

В своем исследовании мы устанавливаем, изучаем характер этих связей в пространственной оценке. Исследовательская проблема: выяснение влияния высокого уровня налоговых преступлений в одних регионах РФ на уровень ухода от уплаты налогов в других.

Кроме пространственных эффектов в данной работе описываются такие факторы, как образование, доверие правительству, налоговая грамотность, гендер, социальные нормы и общение. Влияние этих факторов неоднозначно. Например, социальные нормы имеют неоднозначное влияние на уклонение от налогообложения: с одной стороны, если в обществе принято не уклоняться от налогов, то индивид будет исправно их платить, так как в данном случае к контролю государства добавляется общественный контроль, однако есть люди, которым присуще девиантное поведение, которые из принципа идут наперекор обществу либо люди, которые независимы от общества, таким образом, если в обществе принято платить налоги, то они их платить не будут.

Использование моделей пространственной эконометрики поможет нам получить более точные оценки этих коэффициентов по сравнению с другими моделями, где пространственная эконометрика не использовалась, так как в данном исследовании частично решается проблема пропущенных переменных. 


\section{Обзор литературы}

Разделение факторов, влияющих на уклонение от уплаты налогов, можно сделать по основным сферам устройства общества: политические, экономические, социальные и культурные.

Большинство ученых и практиков считают уклонение от уплаты налогов проявлением неэффективной налоговой системы, этот факт находит подтверждение в статье (Barone, Mocetti, 2011), авторы которой установили, что соблюдение налогообложения выше в ситуациях, когда граждане удовлетворены косвенными выгодами, которые они получают за счет качественного и количественного обеспечения населения, и ниже, в ситуациях, когда они не довольны этим [7], то есть если в стране высокий уровень жизни, то в этой стране люди менее склонны к мошенничеству с налогами.

Доверие к правительству тоже является важным фактором уклонения от налогообложения. По мере роста доверия к правительству уровень соблюдения налогового законодательства также будет расти. Это обусловлено тем, что доверие к правительству положительно влияет на восприятие налоговой справедливости, следовательно, среди налогоплательщиков увеличивается уровень соблюдения налогового законодательства (Sonnur Aktaş Güzela, Gökhan Özerb, Murat Özcan, 2019) [10].

Если же говорить об экономических причинах, то в статье (Carlos Bethencourt, Lars Kunze, 2020) было установлено, что более высокая налоговая ставка увеличивает долю уклоняющихся от уплаты налогов на капитал и трудовые доходы, а также совокупное уклонение от уплаты налогов [3].

Кроме того, важным экономическим фактором является стремление индивидов к максимизации своей прибыли. Эта причина упоминается в статье (Манькова С.В. 2019), автор которой говорит о том, что размер налоговых платежей часто составляет десятки процентов, что в итоге является большой частью дохода. Следовательно, юридические и физические лица начинают искать способы, как законные, так и незаконные для того, чтобы снизить размер оплачиваемых налогов, и оставить большую часть получаемых доходов себе [1].

К социальным факторам можно отнести гендер налогоплательщиков. Было установлено, что гендерный признак оказывает влияние на принятие решения об уплате налогов. Авторы (David M. Bruner, John D’Attoma, Sven Steinmo 2017) в своем исследовании установили: женщины значительно реже соглашаются с тем, что мошенничество с налогами может быть оправдано. Аналогичное исследование провели (Benno Torgler, Neven T. Valev 2010), которое также пришли к выводу, что соблюдение налогового законодательства является более высоким для женщин, несмотря на образование, статус занятости или доход [2, 4].

Важным социальным фактором уклонения от налогообложения является общение, влияние которого рассматривается в статье (Diana Onu, Lynne Oats 2016). Авторы статьи исследовали то, как меняются решения налогоплательщиков при общении или в результате общения с другими людьми о налогах с помощью дискурс-анализа онлайн-форума для веб-дизайнеров. Они описали 5 типов взаимодействия налогоплательщиков и установили, что многие из рассмотренных ими взаимодействий представляют собой активные попытки социального влияния и используют ряд известных методов убеждения. Налогоплательщики активно влияют и убеждают других налогоплательщиков соблюдать налоговое законодательство (и лишь в очень небольшом числе случаев не соблюдать) [6].

Социальные нормы тоже оказывают значительное влияние на налогоплательщиков при принятии решений об уплате налогов. Исследование этого вопроса представлено в работе (John Cullis, Philip Jones, Antonio Savoia 2012), 
авторы которой на основе анализа ответов на опрос людей из Италии и Великобритании выявили, что готовность соблюдать налогообложение чувствительна к сигналам, исходящим от политических лидеров, социальных институтов и наличия процветающих неформальных секторов. Более того, они установили, что социальные нормы меняют ценности, на которые полагаются индивиды при принятии рискованных решений [8].

Ценности индивидов также зависят и от их культурных представлений: культура, религия, образование. Влияние культуры налогоплательщиков на решение об уплате налогов доказывается в статье (Yiannis Kountourisa, Kyriaki Remoundou, 2013). Авторы сравнили налоговое поведение коренных граждан Европейский стран с налоговым поведением иммигрантов. Они выявили, что уплата налогов отдельных налогоплательщиков по крайней мере частично зависит от культуры: мигранты из менее развитых стран, где отсутствуют демократические институты и где налоговые поступления систематически расходуются не по назначению, могут возражать против налогообложения и рассматривать уклонение от уплаты налогов как средство протеста против правительства. Также авторы установили, что культурная интеграция может в среднесрочной и долгосрочной перспективе ослабить этот эффект [12].

В своем исследовании (Steven Stack, Augustine Kposowa. 2006).) рассматривают религию, как важнейшую часть для социальной интеграции и предотвращения девиантного поведения, такого как налоговое мошенничество. По результатам, чем выше уровень религиозности человека, тем ниже приемлемость налогового мошенничества [11].

A (David Rodriguez-Justicia, Bernd Theilen. 2018) изучили фактор «образование». Мораль получателей повышается вместе с образованием, а налоговая мораль вкладчиков понижается, если повышается образование, и уровень образования положительно влияет на дух налогоплательщиков, когда косвенная выгода от социального обеспечения больше [5].

\section{Данные и модели}

В работе используются данные Федеральной службы государственной статистики Российской Федерации [14]. С учетом наличия и достоверности необходимых данных, а также частичным сглаживанием влияния «пропущенных переменных» из-за применения эконометрических методов пространственно-регрессионного анализа были отобраны некоторые переменные, влияние которых на показатель склонности к нарушению налогового законодательства будет исследоваться в работе (табл. 1).

Таблица 1

Факторы, оказывающие влияние на исследуемую переменную

\begin{tabular}{|c|c|l|l|}
\hline № & Обозначение & \multicolumn{1}{|c|}{ Фактор } & \multicolumn{1}{|c|}{ Способ расчета } \\
\hline 1 & х61 & $\begin{array}{l}\text { Склонность к нарушению } \\
\text { налогового } \\
\text { законодательства }\end{array}$ & $\begin{array}{l}\text { Отношение платежей в Бюджет Фонда Со- } \\
\text { циального Страхования Российской Федера- } \\
\text { ции на одного занятого и номинальной зара- } \\
\text { ботной платы. } \\
\text { Показатель в среднем за рассматриваемый } \\
\text { период должен стремиться к 0.029. }\end{array}$ \\
\hline 2 & х56 & $\begin{array}{l}\text { Реальные доходы на душу } \\
\text { населения }\end{array}$ & $\begin{array}{l}\text { Номинальные доходы, разделённые на стои- } \\
\text { мость фиксированного набора потребитель- } \\
\text { ских товаров и услуг }\end{array}$ \\
\hline 3 & х57 & Уровень образованности & $\begin{array}{l}\text { Оценка доли населения с высшим образова- } \\
\text { нием в регионе }\end{array}$ \\
\hline
\end{tabular}




\begin{tabular}{|c|c|c|c|}
\hline 4 & $\mathrm{x} 18$ & $\begin{array}{l}\text { Коэффициент } \\
\text { демографической } \\
\text { нагрузки }\end{array}$ & $\begin{array}{l}\text { Сколько лиц нетрудоспособного возраста } \\
\text { приходится на } 1000 \text { человек трудоспособ- } \\
\text { ного возраста }\end{array}$ \\
\hline 5 & x39 & $\begin{array}{l}\text { Уровень развития } \\
\text { финансовой инфраструк- } \\
\text { туры в регионе }\end{array}$ & $\begin{array}{l}\text { Число кредитных организаций и филиалов в } \\
\text { субъекте }\end{array}$ \\
\hline 6 & $\mathrm{x} 41$ & Уровень преступности & $\begin{array}{l}\text { Число зарегистрированных убийств и поку- } \\
\text { шений }\end{array}$ \\
\hline 7 & $\mathrm{x} 7$ & Уровень заболеваемости & Заболеваемость на 1000 человек населения \\
\hline 8 & $\mathrm{x} 17$ & $\begin{array}{l}\text { Уровень присутствия } \\
\text { женщин }\end{array}$ & На 1000 мужчин приходится женщин \\
\hline 9 & $\mathrm{x} 19$ & Уровень брачности & $\begin{array}{l}\text { Общие коэффициенты брачности на } 1000 \\
\text { человек населения }\end{array}$ \\
\hline 10 & $\mathrm{x} 25$ & Уровень безработицы & $\begin{array}{l}\text { По данным выборочных обследований рабо- } \\
\text { чей силы; в среднем за год }\end{array}$ \\
\hline 11 & $x 53$ & Уровень автомобилизации & $\begin{array}{l}\text { Число собственных легковых автомобилей } \\
\text { на } 1000 \text { человек населения }\end{array}$ \\
\hline 12 & $\mathrm{x} 55$ & $\begin{array}{l}\text { Склонность } \\
\text { к кредитованию }\end{array}$ & $\begin{array}{l}\text { Отношение объема кредитов на одного че- } \\
\text { ловека (без учета нетрудоспособных) к вели- } \\
\text { чине номинальных доходов на душу населе- } \\
\text { ния }\end{array}$ \\
\hline 13 & $\mathrm{x} 28$ & $\begin{array}{l}\text { Уровень производитель- } \\
\text { ности труда }\end{array}$ & Оценка, ВРП на одного занятого \\
\hline
\end{tabular}

Источник: составлено авторами

Для проверки сформированных ранее гипотез будут использованы некоторые модели, в том числе и линейная регрессионная модель на основе пространственной выборки (pooled regression) (1), модели панельных данных с фиксированными (2) и случайными эффектами (3), модели с пространственно-авторегрессионными эффектами $(4,5)$.

$$
\begin{aligned}
& \quad x 61_{i}=\beta_{0}+\beta_{1} * x 56_{i}+\beta_{2} * x 57_{i}+\beta_{3} * x 18_{i}+\beta_{4} * x 39_{i}+\beta_{5} * \\
& x 41_{i}+\beta_{6} * x 7_{i}+\beta_{7} * x 17_{i}+\beta_{8} * x 19+_{i} \beta_{9} * x 25_{i}+\beta_{10} * x 53_{i}+\beta_{11} * \\
& x 55_{i}+\beta_{12} * x 28_{i}+\varepsilon_{i}
\end{aligned}
$$

где, $\beta \_\mathrm{i}-$ коэффициенты регрессии.

$$
\begin{array}{rl}
x 61_{i t}=\alpha_{i}+\beta_{1} & * x 56_{i t}+\beta_{2} * x 57_{i} E_{r_{i t}}+\beta_{3} * x 18_{i t}+\beta_{4} * x 39+\beta_{5} \\
& * x 41_{i t}+\beta_{6} * x 7_{i t}+\beta_{7} * x 17_{i t}+\beta_{8} * x 19_{i t}+\beta_{9} * x 25_{i t} \\
& +\beta_{10} * x 53_{i t}+\beta_{11} * x 55_{i t}+\beta_{12} * x 28_{i t}+\varepsilon_{i t}
\end{array}
$$

где, $\alpha \_$i - выражает индивидуальный эффект объекта i, не зависящий от времени t, при этом регрессоры не содержат константу.

$$
\begin{array}{rl}
x 61_{i t}=\mu+\beta_{1} & * x 56_{i t}+\beta_{2} * x 57_{i} E_{r_{i t}}+\beta_{3} * x 18_{i t}+\beta_{4} * x 39+\beta_{5} \\
& * x 41_{i t}+\beta_{6} * x 7_{i t}+\beta_{7} * x 17_{i t}+\beta_{8} * x 19_{i t}+\beta_{9} * x 25_{i t} \\
& +\beta_{10} * x 53_{i t}+\beta_{11} * x 55_{i t}+\beta_{12} * x 28_{i t}+u_{i t}+\varepsilon_{i t}
\end{array}
$$

где, $\mu$ - константа, $u_{-}$it - случайная ошибка, инвариантная по времени для каждого объекта.

$$
\begin{aligned}
x 61_{i t}=\alpha_{i}+\rho & * W * x 61_{i t}+\beta_{1} * x 56_{i t}+\beta_{2} * x 57_{i} E_{r_{i t}}+\beta_{3} * x 18_{i t}+\beta_{4} * x 39 \\
& +\beta_{5} * x 41_{i t}+\beta_{6} * x 7_{i t}+\beta_{7} * x 17_{i t}+\beta_{8} * x 19_{i t}+\beta_{9} * x 25_{i t} \\
& +\beta_{10} * x 53_{i t}+\beta_{11} * x 55_{i t}+\beta_{12} * x 28_{i t}+\varepsilon_{i t}
\end{aligned}
$$


где, $\mathrm{W}$ - матрица, характеризующая пространственную компоненту в модели, $\rho-$ коэффициент, отражающий наличие пространственных эффектов.

$$
\begin{aligned}
x 61_{i t}=\mu+\rho & * W * x 61_{i t}+\beta_{1} * x 56_{i t}+\beta_{2} * x 57_{i} E_{r_{i t}}+\beta_{3} * x 18_{i t}+\beta_{4} \\
& * x 39+\beta_{5} * x 41_{i t}+\beta_{6} * x 7_{i t}+\beta_{7} * x 17_{i t}+\beta_{8} * x 19_{i t} \\
& +\beta_{9} * x 25_{i t}+\beta_{10} * x 53_{i t}+\beta_{11} * x 55_{i t}+\beta_{12} * x 28_{i t} \\
& +u_{i t}+\varepsilon_{i t}
\end{aligned}
$$

где, $\mu$ - константа, $\mathrm{u}$ _it - случайная ошибка, инвариантная по времени для каждого объекта.

\section{Результаты}

\begin{tabular}{|c|c|c|c|c|c|}
\hline \multirow{2}{*}{ VARIABLES } & (1) & (2) & (3) & (4) & (5) \\
\hline & pooled & $\mathrm{FE}$ & $\mathrm{RE}$ & SAR_FE & SAR_RE \\
\hline \multirow{2}{*}{$\mathrm{x} 56$} & $0.001 * *$ & -0.000 & -0.000 & 0.001 & 0.000 \\
\hline & $(0.000)$ & $(0.000)$ & $(0.000)$ & $(0.000)$ & $(0.000)$ \\
\hline \multirow[t]{2}{*}{$\mathrm{x} 57$} & -0.043 & -0.013 & -0.011 & -0.041 & -0.033 \\
\hline & $(0.046)$ & $(0.054)$ & $(0.051)$ & $(0.049)$ & $(0.048)$ \\
\hline \multirow[t]{2}{*}{$\mathrm{x} 18$} & $0.000 * * *$ & $0.000 * * *$ & $0.000^{* * * *}$ & $0.000 *$ & $0.000 * * *$ \\
\hline & $(0.000)$ & $(0.000)$ & $(0.000)$ & $(0.000)$ & $(0.000)$ \\
\hline \multirow[t]{2}{*}{$\mathrm{x} 39$} & $-0.000 * *$ & 0.000 & 0.000 & 0.000 & -0.000 \\
\hline & $(0.000)$ & $(0.000)$ & $(0.000)$ & $(0.000)$ & $(0.000)$ \\
\hline \multirow[t]{2}{*}{$\mathrm{x} 41$} & $0.000^{* * *}$ & -0.000 & $0.000 * * *$ & -0.000 & $0.000 * *$ \\
\hline & $(0.000)$ & $(0.000)$ & $(0.000)$ & $(0.000)$ & $(0.000)$ \\
\hline \multirow[t]{2}{*}{$\mathrm{x} 7$} & $0.000^{* * *}$ & $0.000^{* *}$ & $0.000^{* * * *}$ & $0.000 *$ & $0.000 * *$ \\
\hline & $(0.000)$ & $(0.000)$ & $(0.000)$ & $(0.000)$ & $(0.000)$ \\
\hline \multirow[t]{2}{*}{$\mathrm{x} 17$} & 0.000 & $-0.000 *$ & 0.000 & $-0.000 *$ & 0.000 \\
\hline & $(0.000)$ & $(0.000)$ & $(0.000)$ & $(0.000)$ & $(0.000)$ \\
\hline \multirow[t]{2}{*}{$\mathrm{x} 19$} & $0.001 * * *$ & $0.001 * * *$ & $0.001 * * *$ & $0.000 * * *$ & $0.000 * * *$ \\
\hline & $(0.000)$ & $(0.000)$ & $(0.000)$ & $(0.000)$ & $(0.000)$ \\
\hline \multirow[t]{2}{*}{$\mathrm{x} 25$} & $-0.000 * * *$ & 0.000 & $-0.000 * *$ & 0.000 & -0.000 \\
\hline & $(0.000)$ & $(0.000)$ & $(0.000)$ & $(0.000)$ & $(0.000)$ \\
\hline \multirow[t]{2}{*}{$\mathrm{x} 53$} & $-0.000 * *$ & -0.000 & -0.000 & -0.000 & -0.000 \\
\hline & $(0.000)$ & $(0.000)$ & $(0.000)$ & $(0.000)$ & $(0.000)$ \\
\hline \multirow[t]{2}{*}{$\mathrm{x} 55$} & $0.000 * * *$ & $-0.000 * * *$ & $-0.000 * * *$ & $-0.000 * *$ & $-0.000 *$ \\
\hline & $(0.000)$ & $(0.000)$ & $(0.000)$ & $(0.000)$ & $(0.000)$ \\
\hline \multirow[t]{2}{*}{$\mathrm{x} 28$} & $-0.000 * * *$ & 0.000 & 0.000 & 0.000 & 0.000 \\
\hline & $(0.000)$ & $(0.000)$ & $(0.000)$ & $(0.000)$ & $(0.000)$ \\
\hline \multirow[t]{2}{*}{ Constant } & -0.004 & $0.029 * *$ & 0.000 & & -0.009 \\
\hline & $(0.003)$ & $(0.013)$ & $(0.006)$ & & $(0.006)$ \\
\hline \multirow[t]{2}{*}{ Spatial rho } & & & & $0.624 * * *$ & $0.698^{* * *}$ \\
\hline & & & & $(0.079)$ & $(0.071)$ \\
\hline Observations & 747 & 747 & 747 & 747 & 747 \\
\hline R-squared & 0.473 & 0.183 & & 0.004 & \\
\hline AIC & -6704 & -7887 & & -7932 & \\
\hline BIC & -6649 & -7832 & & -7872 & \\
\hline $\begin{array}{l}\text { Number of } \\
\text { REGION }\end{array}$ & & 83 & 83 & 83 & 83 \\
\hline
\end{tabular}

Результаты оцененных моделей приведены в табл. 2.

Результаты оцененных моделей

Таблиия 2

Источник: составлено авторами 


\section{Выводы}

Наиболее предпочтительной моделью с учетом результата теста Хаусмана является SAR_FE с AIC равный 7932.

Ключевой вывод заключается в том, что среднее значение показателя уровня ухода от уплаты налогов в соседних регионах положительно влияет на соответствующую величину рассматриваемого региона.

Использование моделей, учитывающих наличие пространственных эффектов, позволило уточнить влияние на исследуемую зависимую переменную факторов, которые ранее уже рассматривались в литературе.

Уровень демографической нагрузки отрицательно влияет на склонность к нарушению налогового законодательства, скорее всего люди старшего поколения будут работать официально, потому что им нужна пенсия, некая стабильность, следовательно они будут исправно платить налоги. Уровень заболеваемости отрицательно влияет на уровень ухода от уплаты налогов, скорее всего это обусловлено тем, что чем больше люди болеют, тем больше у них поводов для обращения в государственные больницы, тем важнее им получить хорошую государственную медицинскую поддержку и налоговые вычеты от работодателя. Уровень брачности отрицательно влияет на уход от уплаты налогов, так как люди, находящиеся в браке, скорее будут вести себя наиболее правильно и законопослушно, потому что они испытывают моральное давление и ответственность за будущее другого человека. Примеры положительного влияния на уход от налогов: уровень присутствия женщин: женщина без семьи, не будет спорить с работодателем и выдвигать свои требования по поводу законности предоставленной работы, скорее всего она пойдет на неофициальную зарплату, чтобы прокормить себя. Показатель склонности к кредитованию положительно влияет на склонность к нарушению налогового законодательства, потому что скорее всего более склонные к риску люди в достаточной степени последовательны.

Результаты исследования можно использовать для проектирования системы, которая позволит создать институциональные условия и правильные стимулы, не позволяющие налогоплательщикам нарушать законодательство.

\section{Дальнейшие исследования}

Предстоит более точно определить понятие склонности к нарушению налогового законодательства, в том числе в контексте различных налогов, а также более содержательно описать субъектов, принимающих конкретные решения и их мотивы.

\section{Список источников / References}

1. Манькова С.В. Наука и образование: отечественный и зарубежный опыт / Манькова С.В. // Двадцатая международная научно-практическая конференция: сборник статей. $-2019$.

2. Benno Torgler, Neven T. Valev. Gender and public attitudes toward corruption and tax evasion / Benno Torgler, Neven T. Valev.// Contemporary Economic Policy. - 2010. - vol.24. $-554-568$.

3. Carlos Bethencourt, Lars Kunze. Social norms and economic growth in a model with labor and capital income tax evasion / Carlos Bethencourt, Lars Kunze // Economic Modelling. 2020. - 86. - 170-182.

4. David M. Bruner, John D'Attoma, Sven Steinmo. The role of gender in the provision of public goods through tax compliance / David M. Bruner, John D'Attoma, Sven Steinmo // Journal of Behavioral and Experimental Economics. - 2017. - 71. - 45-55. 
5. David Rodriguez-Justicia, Bernd Theilen. Education and tax morale / David Rodriguez-Justicia, Bernd // Journal of Economic Psychology. - 2018. - 64. - 18-48.

6. Diana Onu, Lynne Oats. "Paying tax is part of life": Social norms and social influence in tax communications / Diana Onu, Lynne Oats // Journal of Economic Behavior \& Organization. - 2016. - 124. - 29-42.

7. Guglielmo Barone, Sauro Mocetti. Tax morale and public spending inefficiency/ Guglielmo Barone, Sauro Mocetti // International Tax and Public Finance. - 2011. - vol. 18. -724-749.

8. John Cullis, Philip Jones, Antonio Savoia. Social norms and tax compliance: Framing the decision to pay tax / John Cullis, Philip Jones, Antonio Savoia // The Journal of Socio-Economics. - 2012. - 41. - 159-168.

9. Sandro Casal, Christoph Kogler, Luigi Mittone, Erich Kirchler. Tax compliance depends on voice of taxpayers / Sandro Casal, Christoph Kogler, Luigi Mittone, Erich Kirchler // Journal of Economic Psychology. - 2016. - 56. - 141-150.

10. Sonnur Aktaş Güzela, Gökhan Özerb, Murat Özcan. The effect of the variables of tax justice perception and trust in government on tax compliance: The case of Turkey / Sonnur Aktaş Güzela, Gökhan Özerb, Murat Özcan // Journal of Behavioral and Experimental Economics. - 2019. - 78. - 80-86.

11. Steven Stack, Augustine Kposowa. The Effect of Religiosity on Tax Fraud Acceptability: A Cross-National Analysis / Steven Stack, Augustine Kposowa // Journal for the Scientific Study of Religion. - 2006. -45(3). - 325-351.

12. Yiannis Kountourisa, Kyriaki Remoundou. Is there a cultural component in tax morale? Evidence from immigrants in Europe / Yiannis Kountourisa, Kyriaki Remoundou // Journal of Economic Behavior \& Organization. - 2013. - 96. - 104-119.

13. Регионы России. Социально-экономические показатели. 2019. [Электронный ресурс]. - URL: https://rosstat.gov.ru/folder/210/document/13204

\section{Сведения об авторах / About authors}

Нагапетян Артур Рубикович, канд. экон. наук, старший преподаватель Департамента экономических наук, Школа экономики и менеджмента, Дальневосточный федеральный университет. 690022 Россия, г. Владивосток, о-в Русский, кампус ДВФУ, корпус G.

E-mail: nagapetyan_ar@dvfu.ru

Artur R. Nagapetyan, Candidate of Economic Sciences, Senior Lecturer at the Department of Economic Sciences, School of Economics and Management, Far Eastern Federal University. Building G, FEFU campus, Russky Island, Vladivostok, Russia 690922. E-mail: nagapetyan_ar@dvfu.ru

Бонячук Мария Вадимовна, студент, Школа экономики и менеджмента, Дальневосточный федеральный университет. 690022 Россия, г. Владивосток, о-в Русский, кампус ДВФУ, корпус G.

E-mail: popov.mal@students.dvfu.ru

Mariya V. Bonyachuk, Student, School of Economics and Management, Far Eastern Federal University. Building G, FEFU campus, Russky Island, Vladivostok, Russia 690922.

E-mail: popov.mal@students.dvfu.ru

Григорьева Валерия Игоревна, студент, Школа экономики и менеджмента, Дальневосточный федеральный университет. 690022 Россия, г. Владивосток, о-в Русский, кампус ДВФУ, корпус G. Email: petrukhina.ase@students.dvfu.ru

Valeriya I. Grigoryeva, Student, School of Economics and Management, Far Eastern Federal University. Building G, FEFU campus, Russky Island, Vladivostok, Russia 690922.

E-mail: petrukhina.ase@students.dvfu.ru

(C) Нагапеятн А.Р., Бонячук М.В., Григорьева В.И. (C) Nagapetyan A.R., Bonyachuk M.V., Grigoryeva V.I. Адрес сайта в сети интернет: http://jem.dvfu.ru 